\title{
Correction to: GPU-accelerated scanning path optimization in particle cancer therapy
}

\author{
Chao $\mathrm{Wu}^{1,2} \cdot$ Yue-Hu Pu${ }^{1,3} \cdot$ Xiao Zhang ${ }^{3}$
}

Published online: 23 April 2019

(C) China Science Publishing \& Media Ltd. (Science Press), Shanghai Institute of Applied Physics, the Chinese Academy of Sciences, Chinese Nuclear Society and Springer Nature Singapore Pte Ltd. 2019

\section{Correction to: NUCL SCI TECH (2019) 30:56 https://doi.org/10.1007/s41365-019-0582-6}

In the original article the authors affiliations are incorrectly published.
The authors correct affiliations are provided in this correction article.

The original article can be found online at https:// doi.org/10.1007/s41365-019-0582-6.

Yue-Hu Pu

puyuehu@sinap.ac.cn

1 Shanghai Institute of Applied Physics, Chinese Academy of Sciences, Shanghai 201800, China

2 University of Chinese Academy of Sciences, Beijing 100049, China

3 Shanghai APACTRON Particle Equipment Co. Ltd, Shanghai 201800, China 